\title{
CLIMA E HIPÓTESIS DE CAMBIO CLIMÁTICO EN LA REGIÓN GEOGRÁFICA DEL SURESTE IBÉRICO
}

\author{
Antonio Gil Olcina \\ Instituto Universitario de Geografía \\ Universidad de Alicante
}

El reconocimiento de una región geográfica, más allá de las puramente climática o natural, dice de la estrecha relación histórica y actual entre medio y hombre; de la incansable lucha de éste para hacer de aquél, con agobiante déficit hídrico, un espacio útil o, incluso, puntero en actividades económicas que requieren, en primer término, agua, adaptándose primero a una pluviometría adversa, garantizando el suministro de agua de boca, incrementando las disponibilidades para riego a través de una ejecutoria hidráulica impar, y, en última instancia, convirtiendo la falta de lluvia en una ventaja adicional para la horticultura de ciclo manipulado.

Así pues, el problema secular ha sido, y es, el agua, debido tanto al régimen pluviométrico como a la red hidrográfica, integrada ésta, fuera de los ríos Segura y Grande de Adra, por ramblas, barrancos y, en el mejor de los casos, ríos-ramblas (Amadorio, Monnegre, Vinalopó, Guadalentín, Almanzora, Andarax), cursos éstos de carácter híbrido, más identificados no obstante con las segundas (GIL OLCINA, 2004).

Parientes enflaquecidos de los ríos mediterráneos autóctonos, los ríos-ramblas, razón y fundamento de los grandes regadíos deficitarios del sureste ibérico, ofrecen los rasgos esenciales siguiente: escasa abundancia, débil coeficiente de escorrentía, módulo específico ínfimo, fortísima irregularidad interanual, máximos equinocciales, profundo mínimo estival y fabulosas crecidas. En íntima conexión con estas colosales avenidas y las enérgicas ablaciones originadas, sobre materiales deleznables, y despojados de vegetación por los torrenciales aguaceros que causan aquéllas, las corrientes desmadradas arrastran ingentes cargas sólidas, que han configurado amplios llanos de inundación y extensos conos aluviales, formas de relieve propicias al desarrollo de dilatadas redes de riego.

Merced a sus exiguos módulos, amplios lechos mayores, los ríos-ramblas surestinos dieron pie al desarrollo de los más célebres regadíos deficitarios de la vertiente mediterránea española (Vega de Lorca, Regadío de Elche y Huerta de Alicante), con la mayor parte de sus respectivas superficies, auténticos campos regados, dedicadas a la cerealicultura y a una arboricultura de escasas exigencias hídricas. La fuerte desproporción entre agua disponible y espacio beneficiado favoreció la disociación entre las propiedades de agua y tierra, así como iniciativas para el incremento de los recursos hídricos, concretadas en el 
planteamiento de trasvases ya en el otoño de la Edad Media y, sobre todo, en la temprana construcción de embalses (Tibi, Elche, Relleu, Puentes, Valdeinfierno). Subrayemos, por otra parte, que los ríos-ramblas surestinos son los únicos cursos de agua en la Península donde se produjo la separación entre las propiedades de agua y tierra, hecho de singular trascendencia y plenamente operativo aún en las primeras décadas del siglo XX (GIL OLCINA, 1993).

Mediado el ochocientos, el abastecimiento a poblaciones en la región geográfica del sureste ibérico ofrecía rasgos enteramente preindustriales, ninguna de las ciudades disponía de las infraestructuras precisas para un suministro adecuado; y continuó siendo muy precario hasta que, tras la guerra civil de 1936-39, la Mancomunidad de los Canales del Taibilla, creada en 1927, fue una realidad operativa. En la actualidad, combinada con el trasvase Tajo-Segura, sin que falte la aportación complementaria, y hasta ahora razonable, de la desalinización, constituyen el mayor complejo hidráulico de España, que, merced a todo ello, garantiza el agua de boca en buena parte del seco sureste ibérico.

Otra muestra digna de mención, en esa respuesta humana al desafío del medio que ha configurado sobre éste la región geográfica del sureste ibérico, es el Consorcio de Aguas de la Marina Baja, para prevenir una situación como la de septiembre de 1978, cuando fue preciso abastecer desde Alicante, con agua de la Mancomunidad de Canales del Taibilla, mediante buques-cisternas, al importante núcleo turístico de Benidorm. Con inteligente planteamiento y la más avanzada tecnología, el Consorcio armoniza, a satisfacción de todos, las demandas urbana y agrícola de agua, hasta entonces conflictivas.

Con todo, ha de tenerse muy presente que, en una economía de amplia y casi exclusiva base agraria durante siglos, y donde aún hoy la aportación del complejo agroindustrial al PIB es considerable, la relación hombre-medio se ha anudado y robustecido a través de una actividad agraria desarrollada bajo condicionamientos pluviométricos bien adversos. La región geográfica del sureste ibérico plantea inconvenientes y ofrece posibilidades al aprovechamiento del suelo, la explotación de éstas y la superación de aquéllos integran un proceso histórico altamente condicionado por factores económicos y técnicos, donde el agua constituye referencia primordial, ya sea en secano, regadío eventual, regadío deficitario, huerta propiamente dicha o nuevos sistemas de producción agrícola. Modalidades peculiares de dicho ámbito han sido regadíos de turbias y campos regados; y, en abierto contraste con ellos, es de resaltar la posición cimera de la mencionada región geográfica en la horticultura de ciclo manipulado española, cuya valoración de la lluvia in situ es radicalmente opuesta a la de la agricultura tradicional.

En el transcurso de los últimos siete lustros, las nuevas tecnologías y sistemas de cultivo han permitido no sólo superar las desventajas climáticas y sacar el máximo provecho de las posibilidades que deparan régimen térmico, elevada insolación y reducido recorrido del viento, sino beneficiarse de la mayor de aquéllas; aunque ésta, que conlleva la pobreza de recursos hídricos propios, no deje de suponer un serio inconveniente, que ha originado una grave sobreexplotación de acuíferos. Parece ocioso encarecer que la dificultad y limitación esencial para los cultivos tradicionales ha sido siempre el régimen de precipitaciones, caracterizados por la escasez, irregularidad y fuerte concentración horaria de las mismas. Es de notar, asimismo, que el enorme potencial energético y lumínico, fundamento de la horticultura del ciclo manipulado, que proporcionan casi tres mil horas de sol (AlicanteCiudad Jardín, 2.896) anuales, de ellas cerca de 1.200 en el período de octubre a marzo, habían contado más como rémora, al intensificar la evapotraspiración, que condición favorable para una cerealicultura azarosa y, las más de veces, con parcos rendimientos. En cambio, la baja frecuencia de precipitaciones constituye para la horticultura de ciclo manipulado una ventaja adicional. Para esta agricultura de vanguardia, bajo abrigo de 
plástico o al aire libre, controlada al máximo, la lluvia in situ, y en particular el aguacero de elevada intensidad horaria, representa, por lo general, un serio inconveniente, ya que pueden estropear las cosechas, dañar los cobertizos de plástico, perturbar la planificación o propiciar ciertas plagas.

La agricultura altamente tecnificada demanda agua, traída a veces de distancias considerables, y a precio elevado, pero, por las razones apuntadas, no casa con la lluvia in situ. Así pues, las valoraciones de esta última por agricultores tradicionales, de una parte, e innovadores, por otra, son antitéticas. Su infrecuencia, pesadilla de los primeros, constituye para los segundos una ventaja más (GIL OLCINA, 2004). Sin embargo, a pesar de esa llamativa mutación, auténtico giro copernicano, el déficit de agua no ha hecho sino intensificarse en los últimos años; para enjugarlo o, al menos, paliarlo, se recurrió a la extracción desmedida y excesiva de recursos hipogeos, con situaciones rayanas o plenamente incursas en la sobreexplotación de acuíferos, cuya secuela más dañina es la salinización, Así, aridez, salinidad y agricultura de alto valor se dan hoy cita en la región geográfica del sureste ibérico, fachada mediterránea de tierras costeras y prelitorales apoyadas en las montañas béticas, que, con unos $40 \mathrm{~km}$ de anchura media, se extiende entre el alicantino cabo de La Nao y el granadino Sacratif, entre los paralelos $38^{\circ} 45^{\prime}$ y $36^{\circ} 45^{\prime}$ Norte.

En estas tierras, de régimen pluviométrico extremo y dispar, que conjuga prolongadas e intensas sequías con esporádicos diluvios, responsables de rogativas ad petendam pluviam y pro serenitate, donde no faltan olas de calos estivales y en las estaciones aledañas, mientras son menos frecuentes y marcadas las de fríos, por la doble defensa de latitud y relieve, que hacen de las temperaturas negativas una rareza en la franja litoral; aquí, en la región geográfica del sureste ibérico, donde parece que ninguna manifestación pluviométrica debiera sorprender, han sido éstas las que han procurado familiaridad y credibilidad entre el gran público a hipótesis de cambios climáticos inducidos por el hombre, es decir, la deforestación mediado el ochocientos (GIL OLCINA, 2007) y el efecto invernadero en la actualidad.

La región geográfica del sureste ibérico es la más seca de la Península y de Europa; su corazón, el arco costero murcianoalmeriense de Tiñoso a Gata, recibe menos de 200 $\mathrm{mm}$ anuales de lluvia media y en el último de estos cabos, que posee rango de polo seco del continente, queda en torno a $125 \mathrm{~mm}$, más o menos según la serie considerada; y, además, este ínfimo valor sólo cobra pleno significado si se tiene presente que algunos años prácticamente no llueve. Así pues, las precipitaciones son parvas, y los días en que se producen también, ya que no exceden, en los observatorios menos desfavorecidos, de medio centenar; menudean, por contra, los días despejados y sin apenas nubosidad: Lorca es la «ciudad del sol» en el «serenísimo reino de Murcia».

Se registran, en síntesis, precipitaciones reducidas y, con frecuencia, intensas, fruto de contados chaparrones, algunos torrenciales y de extraordinaria violencia. Este régimen pluviométrico, que conjuga duras y prolongadas sequías con esporádicos diluvios, resulta de una situación meridional y marginal en la zona de circulación general del oeste, y a sotavento de la misma, así como de la ubicación retraída en la cuenca del mediterráneo occidental, vecindad de la subsidencia subtropical y del desierto sahariano, trazado costero e incidencia del relieve. En efecto, el sureste peninsular ocupa una posición periférica y de abrigo en la gran zona de flujo dominante del oeste; ello conlleva, máxime si se tiene en cuenta el bastión montañoso de las cordilleras béticas, que ocasionan efecto foehn sobre los vientos de componente oeste, una mínima repercusión pluviométrica de los mismos, suplantados por la subsidencia subtropical en estío y, aun con cierta frecuencia, en las estaciones de primavera y otoño. 
Añadamos que las precipitaciones no sólo son exiguas sino muy irregulares, con su efectividad mermada también por su fuerte concentración horaria, cuantiosa evapotranspiración potencial y verano seco. Las horas de sol al año son casi tres mil y, como mínimo, la evapotranspiración potencial duplica la pluviometría media anual. Corolario obligado de todo ello es la aridez, que constituye el rasgo definitorio primordial de la región climática del sureste ibérico. Con cualquier índice termopluviométrico, hídrico, de acuosidad o aridez, esta última peculiaridad queda, siempre, bien patente.

El dato de precipitación media anual, componente esencial del déficit hídrico que sufre la región geográfica considerada, no evidencia, empero, la elevada irregularidad interanual, con largas y durísimas secas. Con motivo la peor de que hay noticia histórica, un Real Decreto de 30 de marzo de 1850 dispuso la apertura de «concurso público para adjudicar un premio al autor de la memoria que mejor desempeñe, a juicio de los censores que S.M. se reserva designar, el tema siguiente: Determinar las causas que producen las constantes sequías de las provincias de Murcia y Almería, señalando los medios de removerlas, si fuese posible; y no siéndolo, de atenuar sus efectos»; obedecía la convocatoria a la creencia de que dichas calamidades podían obedecer a un cambio climático originado por la deforestación; lustros después, en marzo de 1885, y en estrecha relación con la desastrosa riada de «Santa Teresa», el 14-15 de octubre de 1879, en el Segura, se reuniría en Murcia el «Congreso contra las inundaciones en la región de Levante». Ambas iniciativas suponen precedentes del mayor interés en el estudio científico de esos desastres, manifestaciones opuestas de un régimen pluviométrico extremadamente desigual. No cabe desconocer, sin embargo, que la escasez hídrica representa el problema esencial mientras los aguaceros torrenciales y desaforados, sumamente dañinos y muchas veces mortíferos, revisten carácter ocasional, con períodos de retorno estadísticamente amplios, si bien tampoco puede olvidarse que nada excluye su repetición en un breve lapso de tiempo.

Como se ha dicho, característica básica de la expresada región geográfica es la pobreza en agua, cuyo déficit para uso agrícola y abastecimiento tampoco enjuga una red hidrográfica carente, salvo el Segura y, en menor medida, el río Adra, de cursos alóctonos con cabeceras abundantes. En esta tierra reseca y sedienta poseen carta de naturaleza grandes aljibes, boqueras, laderas aterrazadas, cimbres, foggaras, presas subálveas, norias, molinos de arcaduces, reservorios antiguos colmatados o disminuidos por los tarquines, y, más recientemente, menguados trasvases y una gravísima sobreexplotación de acuíferos. Aquí, como afirmara Brunhes, el agua es el bien por excelencia y, disociada de la tierra en grandes regadíos deficitarios, constituyó pertenencia incomparablemente más valiosa y ambicionada que ésta (GIL OLCINA, 1993).

A pesar de la aceptación generalizada del reducido volumen de precipitaciones como referencia esencial, la definición de la región climática del sueste ibérico no deja de plantear dificultades, comenzando por la propia elección de dicho umbral. Sucesivamente, con clara tendencia al alza, se han propuesto las isoyetas medias de 300 (VILÁ, 1961) y 350 mm anuales, mientras aquí, por razones que luego se aducirán, se opta por la de 375. Con todo, no parece que la sola y exclusiva referencia a un dato pluviométrico, por más que sintetice otras consideraciones, resulte suficiente para la delimitación; de ahí el recurso a otros como las temperaturas, días despejados y horas de sol. No parece, en efecto, que deba prescindirse de la benignidad del invierno, tan pródiga en consecuencias, que denuncia la influencia mediterránea, ni tampoco del potencial energético y lumínico que supone casi 3.000 horas de sol anuales.

Altitud y continentalidad crecientes, aunque no exista intensificación orográfica significativa de las precipitaciones acaban por excluir de la región geográfica del sureste peninsular, ya que conllevan endurecimiento del invierno, descenso de la temperatura media anual e incremento de la amplitud térmica; con carácter general, parece que no deban adscribirse 
al mencionado espacio observatorios cuya media mensual más fría (enero o, en algún caso, diciembre) baje de $8^{\circ} \mathrm{C}$, la amplitud térmica suba de $18^{\circ}$ y la media anual no alcance $16^{\circ}$ C. Las tierras integrantes de este espacio climático son litorales o prelitorales, una fachada mediterránea apoyada en las montañas.

\section{Consecuencias climáticas de la situación y del relieve}

Situada entre los paralelos $38^{\circ} 45^{\prime}$ y $36^{\circ} 45^{\prime} \mathrm{N}$, del cabo alicantino de la Nao al granadino Sacratif, la región geográfica del sureste ibérico ocupa una posición periférica y meridional en la zona de circulación general del oeste. De ello derivan dos hechos de singular trascendencia climática: vecindad de la subsidencia subtropical y alejamiento de las trayectorias habituales de la corriente en chorro templada, que suele discurrir a latitudes superiores a $45^{\circ}$. Como ya se ha indicado, datos de la mayor trascendencia son asimismo la ubicación a sotavento de los vientos del oeste, la inmediatez del Mediterráneo y la cercanía del continente africano. Protagonismo de primer orden asume igualmente el relieve, que determina importante disimetría pluviométrica y efecto foehn. Tampoco es desdeñable la influencia del trazado costero, con cambio de rumbo desde el cabo de la Nao.

Ninguno de los mecanismos climáticos que interaccionan en el sureste ibérico posee una proyección equiparable a la de la subsidencia subtropical, no sólo como causa primordial del máximo de Azores, principal centro de acción en este ámbito, sino también por su responsabilidad capital, con elevado índice NAO, en las más intensas y prolongadas sequías, así como en la penuria estival de precipitaciones, ya que el verano seco es un rasgo de subtropicalidad y no de mediterraneidad, aseveración ésta última tan arraigada y difundida como errónea y carente de todo fundamento. A la hora de justificar la poquedad e irregularidad pluviométricas de esta región climática ningún factor iguala, sin desconocer e infravalorar otros, a la subsidencia subtropical, hegemónica en estío, durante buena parte de otoño y primavera una mayoría de veces, incluso la práctica totalidad del año con ocasión de las peores sequías.

Se ha destacado asimismo, como merece, la condición de sotavento propia del sureste ibérico, al abrigo longitudinal de la influencia atlántica, cuyo debilitamiento hacia dicha área agrava aún más el relieve, tal y como atestiguan gráficamente las imágenes de los satélites meteorológicos. En efecto, al alejamiento longitudinal se suma el cierre montañoso que imponen las sierras de Cazorla, Segura, La Sagra, Taibilla, Alcaraz y Calar del Mundo a los mistrales, mientras hace otro tanto el grandioso edificio de Sierra Nevada con ponientes y garbinos o lebeches. La podera pantalla orográfica bética produce, simultáneamente, efecto foehn, disimetría y sombra pluviométricas, al tiempo que frena o, incluso, ancla las borrascas atlánticas que descienden a estas latitudes. Muy acusadas resultan las disimetrías pluviométricas, ya que mientras los observatorios a barlovento rondan o exceden la altura de $1 \mathrm{~m}$ anual, los menos favorecidos, en determinados tramos de la franja costera no llegan a $200 \mathrm{~mm}$, y mientras aquellas precipitaciones son, en su práctica totalidad de procedencia atlántica, ocurre a la inversa con las segundas, en general mediterráneas.

Contra una creencia muy extendida, el Mediterráneo es «mar de lluvias», por sus condicionamientos térmicos y dinámicos. Grandioso reservorio de agua y calorías, enriquece en ambas a las masas de aire que acceden a la cubeta por sus estrechos portillos meteorológicos, proporcionándoles así los ingredientes esenciales para la génesis de gigantescas nubes puestas en pie, colosales cumulonimbos que interesan todo el espesor de la troposfera. Como se ha indicado, los factores de inestabilidad son también dinámicos, en relación sobre todo con el poderoso cíngulo montañoso casi continuo que ciñe el borde septentrional de la cuenca del Mediterráneo occidental; merced a su existencia, entran en juego una serie de procesos, 
como el principio de conservación del torbellino absoluto, su manifestación específica del efecto hidrodinámico del obstáculo o el efecto de descarga, por inducción hidrodinámica, de las corrientes en chorro. Añadamos que, en otoño e invierno, se establece un acusado gradiente horizontal de temperatura mar-tierra, que proporciona a las advecciones de aire supramediterráneo, para esta época del año, una apreciable ventaja térmica inicial, en torno a $6-8^{\circ} \mathrm{C}$, que presta base a su ascenso. Destacable resulta asimismo, por el elevado calor específico de las aguas marinas, el papel del Mediterráneo como regulador térmico, que, hasta donde es sensible su influencia, dulcifica el invierno, hace más soportable el caluroso verano, traza una curva anual de temperaturas menos accidentada que la de las tierras interiores, con tendencia al aplanamiento, y retrasa la ubicación en ella de los meses con las medias extremas (enero y agosto, respectivamente). Advirtamos, no obstante, que la condición de «mar entre tierras» supone una innegable filiación continental, traducida en una amplitud térmica anual para los observatorios surestinos $\left(14-16^{\circ} \mathrm{C}\right)$ que casi duplica a la de los climas oceánicos peninsulares.

Ha de subrayarse también que, con referencia los flujos del oeste, el Sureste, igual que el resto de la Península, queda de espaldas al Mediterráneo, como confín occidental del mismo. Ello motiva que las consecuencias de los flujos de componente este u oeste resulten diametralmente opuestas, y así lo expresa un refrán muy difundido, que reza: «Lo que en tres días moja el Levante, en una hora lo seca el poniente «. En efecto, el primero aporta aire supramediterráneo, enriquecido energética e hídricamente en contacto con las tibias aguas marinas, proclive al ascenso y, en determinadas circunstancias, al disparo en la vertical; por el contrario, el flujo del oeste, en su descenso desde la Meseta sobre los llanos litorales alicantinos, resulta catabático y experimenta efecto foehn en aire libre, calentándose y alejándose del punto de rocío, con intenso poder desecante, sobre todo en estío, al alcanzar elevada temperatura y reducir la humedad relativa a valores en torno al $25 \%$. Incluso con flujos perturbados, la doble condición de sotavento longitudinal y orográfico debilita mucho la incidencia pluviométrica de las borrascas atlánticas; que portan, en la región geográfica analizada menos del $10 \%$ de la precipitación media anual.

Recordemos igualmente la proximidad del desierto sahariano, inmenso hogar de aire tropical continental, masa ésta que, en función del relieve isobárico y época del año, inhibe las precipitaciones, las embarra o, incluso, potencia. El primero de estos fenómenos es consustancial a advecciones meridianas de aire sahariano, causantes de golpes u olas de calor; la estabilidad está igualmente garantizada por la presencia en los niveles superiores de crestas subtropicales o anchas dorsales protectoras de aire cálido. A diferencia, aire tropical continental en origen supone un serio riesgo potencial de aguaceros muy copiosos e intensos cuando un largo recorrido sobre las aguas mediterráneas, con viaje de ida y vuelta, le permite enjugar su déficit hídrico y adquirir una elevada humedad específica.

Por último, el trazado de la costa tampoco es ajeno a la distribución espacial de precipitaciones; ejemplo prototípico de ello constituye el cambio de rumbo del litoral al sur del cabo de la Nao, que, al trocar el de NE-SW por NW-SE, resguarda de los temporales del noreste, y motiva que, con pocos kilómetros de distancia, los volúmenes de precipitación del Marquesat o Marina Alta (Denia, $674 \mathrm{~mm}$ ) se reduzcan a la mitad en la Marina Baja (Benidorm, 344).

\section{Estabilidad e inestabilidad atmosféricas}

Sin necesidad de incurrir en la exageración retórica de Costa, para quien «regiones hay como la de Murcia, apellidada el serenísimo reino, donde pasan años sin que se vea una sola nube», resulta bien patente que en las tierras del sureste ibérico no menudean 
los días con precipitación ni de cielos cubiertos, priva, por el contrario, el llamado, con calificación que tradicionalmente ha parecido aquí irónica y cuestionable, «buen tiempo»; preponderancia ésta acorde con la de las altas presiones subtropicales en las troposferas media y alta durante el seco verano, en situaciones que habitualmente se anticipan y siguen buena parte de la primavera, para alcanzar, incluso con sucesivos «veranillos», los meses tardoestivales. Subrayemos asimismo que la eficacia pluviométrica de las corrientes perturbadas del noroeste, oeste y suroeste, merced a la protección de las sierras béticas, que deparan efecto foehn y las transforman en catabáticas, es limitada y, a veces, nula. Salvo contadas excepciones, las precipitaciones aportadas por las borrascas atlánticas son moderadas $\mathrm{y}$, con frecuencia, escasas.

Por otra parte, es de resaltar que, frente a una creencia muy extendida el «mal tiempo» en esta región climática, mayoritariamente con génesis mediterránea, infrecuentemente, pero no es efímero, dadas las situaciones que lo originan, vinculadas generalmente a irrupciones de aire anormalmente frío en los niveles superiores, que de manera inexacta y abusiva los medios de comunicación suelen englobar bajo la socorrida denominación de «gota fría», en ocasiones sin que tan siquiera se haya formalizado embolsamiento de aire frío. Es de notar, al respecto, que, con el precedente de las catastróficas inundaciones de 19 de octubre de 1973 en las cuencas del Guadalentín y Almanzora, ocasionadas, éstas sí, por un proceso de «gota fría», a lo largo de la fachada mediterránea española se ha producido desde la década de los ochenta de la centuria anterior, pródiga en riadas, una sinonimia errónea, y a todas luces improcedente, entre «gota fría» y aguacero copioso de gran intensidad horaria. Y en modo alguno es así: la presencia de una «gota fría», en la acepción prístina de Scherag, creador del concepto hace más de sesenta años, no implica necesariamente el segundo, ni éste tiene, obligadamente, por causa a aquélla. Se trata, en suma, de un concepto que en España, y sobre todo en el sureste ibérico, ha conocido, merced a los media, una extraordinaria difusión entre el gran público, en serio detrimento de su precisión. Hoy, mientras algunos especialistas pugnan por recobrar su significado originario, otros cuestionan la propia oportunidad de la expresión y prefieren hablar de «embolsamiento de aire frío» o «depresión fría en altitud».

Llegados a este punto, resulta obligado encarecer que las situaciones causantes, a través de nubes de fuerte desarrollo vertical, con techo en la tropopausa misma, de aguaceros torrenciales son diversas en superficie y altitud. Así, entre las primeras, que guardan estrecha relación con las segundas, reconozcamos, entre otras, las siguientes: baja cerrada centrada entre el Mar de Alborán y la costa argelina, baja argelina acompañada de mínimo simultáneo en el Golfo de Cádiz, baja argelina con mínimo simultáneo en el sur de Italia, depresión sahariana de gran extensión y escasa curvatura, con eje perpendicular a los meridianos, y, por último, gran anticiclón europeo de bloqueo y eje asimismo normal a los meridianos (GALLEGO, 1996). Quizá con alguna excepción, que apuntaremos, estos relieves isobáricos son consecuencia de las topografías de altitud o, en todo caso, de reducida eficacia pluviométrica disociadas de las mismas; resaltemos, empero, que todas ellas tienen por denominador común la movilización, con vientos del primer o segundo cuadrantes (gregales, levantes o sirocos), de aire procedente del Mediterráneo muy inestable y con elevada tensión de vapor, habitualmente superior a $20 \mathrm{~mm} \mathrm{Hg}$., valor que implica cuantiosa disponibilidad de energía y agua, merced al intenso proceso de evaporación a expensas de las tibias aguas mediterráneas. Percutores del disparo en la vertical de este aire con elevada humedad específica y próximo a la saturación o saturado, capaz de ascender desde niveles bajos con reducido gradiente pseudodiabático, son, conjunta o separadamente, la convergencia nacida de la rotación ciclónica de vientos y la convección forzada impuesta por las alineaciones montañosas litorales y prelitorales. 
En suma, ha de destacarse que los mecanismos capaces de proyectar este aire con alta relación de mezcla, fracción de saturación cuyo valor ronda la unidad y muy inestable, hasta el límite de la troposfera son varios y no se limitan a los procesos de «gota fría»; añadamos, cuando menos, depresiones aisladas en altitud, vaguadas retrógradas o meridianas, sistemas convectivos de mesoscala, desarrollos ciclogenéticos, frentes fríos anabáticos de ciclones extratropicales que ingresan por Gibraltar y hasta, en determinadas circunstancias, la convección forzada por el relieve de un flujo de las expresadas características. Aspecto éste digno de mención, por cuanto la explicación del fenómeno se centra en superficie, con el solo requisito en altitud de que la curva de estado no imponga la estabilidad absoluta. Una situación de esta naturaleza requiere un aire en superficie con una tensión de vapor de 25-30 mm Hg y extremadamente inestable, condiciones que pueden darse en un aire tropical continental en origen que enjuga su fuerte déficit hídrico mediante un largo recorrido de ida y vuelta en el seno de una gran depresión sahariana de reducida curvatura y eje perpendicular a los meridianos que desborda ampliamente sobre el Mediterráneo. Una situación de este tipo ocasionó las anegaciones de La Safor y Vega Baja del Segura la primera semana de noviembre de 1987.

\section{Precipitaciones escasas, irregulares e intensas}

Los observatorios meteorológicos de la región climática del sureste ibérico, sin excepción, registran precipitaciones medias inferiores a $375 \mathrm{~mm}$ anuales, casi todos a 350 y muchos a $300 \mathrm{~mm}$, tal y como atestigua la muestra siguiente: Benidorm, 344; Villajoyosa, 322; Alicante, 321; Elche, 306; Monforte, 282; Guardamar, 287; Orihuela, 317; Torrevieja, 217; La Mata, 178; 332, San Javier; 364, Cabo de Palos; 278, Fortuna; 290, Abanilla; 256, en Cartagena; 297, Mazarrón; 149, Cabo Tiñoso; 183, Faro de Águilas; Cabo de Gata, 125; Almería, 227; Murcia, 300; Alcantarilla, 301; Lorca, 248 y Puerto Lumbreras, 246 milímetros. Así pues, rasgo común es la poquedad de las precipitaciones, cuyos totales anuales medios figuran entre los $125 \mathrm{~mm}$ de Cabo de Gata, más o poco menos según la serie escogida, y valores triples de otros que casi marcan el límite fuera del cual los climas secos ceden sitio a mediterráneos poco lluviosos. Las precipitaciones son, como se ve, escasas y los días en que se producen también, ya que no exceden de medio centenar, por doquier bajan de cuarenta y en algunos observatorios no llegan a treinta; en general, los días cubiertos no pasan de 50, mientras suman el doble los despejados. Así, en Alicante los días cubiertos son 35 y 50 los despejados, además los de nubosidad no superior a 2 octas suponen casi la mitad y llegan al 53,9\% los que no exceden de 3 octas. Se registran, en síntesis, precipitaciones exiguas y muy concentradas en el tiempo, fruto de contados chaparrones, en ocasiones de extraordinaria violencia.

La parvedad de las precipitaciones se agrava por la elevada irregularidad interanual de las mismas, con presencia de durísimas y prolongadas sequías. Los cocientes entre los totales del año más y menos lluvioso de las series en los distintos observatorios no bajan del valor 4 , abundan los que arrojan cifras entre 4 y 5 , no faltan los comprendidos entre este último dígito y el coeficiente 10 , y, por último, en algunos puntos e intervalos aparecen, con denominadores prácticamente nulos, cocientes de orden casi infinito. El coeficiente de variación es del $40 \%$ en el Mar Menor y no baja del $60 \%$ en el sector costero entre los cabos Tiñoso y de Gata. A efectos estadísticos, no puede tenerse por normal un período de 30 años, sino que, para obtener datos pluviométricos precisos, ha de ampliarse considerablemente.

Otro dato de la mayor importancia radica en la elevada intensidad horaria de las precipitaciones. Las alturas máximas de éstas en 24 horas, y casi siempre en un intervalo 
bastante menor, de cada mes representan porcentajes notables sobre la precipitación media anual; chaparrones de 25 a $50 \mathrm{~mm}$ en una hora no son extraños, más esporádicas resultan trombas de agua que arrojan el centenar de milímetros en menos de un día, cifra que puede ser ampliamente superada por aguaceros muy copiosos y de excepcional intensidad horaria. En unas pocas horas puede excederse y, en algún caso, duplicarse con creces la precipitación media anual.

Se dice coloquialmente que en este ámbito «no sabe llover», para referirse a precipitaciones muy intensas y breves; en consecuencia, una forma de llover infrecuente y, con frecuencia, violenta. Significativo es, sin duda, que, a diferencia de otras regiones españolas, donde la llovizna posee denominaciones propias, como las de orvallo en Galicia, calabobos en Castilla, aguarrías en Cantabria o xirimiri en el País Vasco, no la posea en la región climática del sureste ibérico, al abrigo de las perturbaciones atlánticas, y donde los mecanismos antes aludidos suelen reintegrar con violencia, eso sí pocas veces y en corto espacio de tiempo, el agua transportada por levantes y, en menor medida, gregales y sirocos.

Tradicional acomodo a esta fuerte intensidad horaria de la lluvia, pleno de sabiduría empírica, ha constituido el regadío eventual de turbias, con sus modalidades, a veces combinadas, de terrazas, boqueras, agüeras y presas de ladera, para proporcionar a los bancales un suplemento hídrico a expensas de estos aguaceros, cuyas escorrentías, de otro modo, se concentran, sin beneficio o con daño, en barrancos, ramblas y ríos-ramblas.

Sin perjuicio de que el conjunto de mecanismos ya aludidos puedan, a veces, originar situaciones de fortísima inestabilidad atmosférica, con volúmenes de lluvia más que generosos catastróficos, los totales medios anuales son exiguos, menguados por la ineficacia, en este sotavento oriental cerrado por las montañas a los flujos de componente oeste, de las borrascas atlánticas y la baja frecuencia de los tipos de tiempo que traen agua mediterránea. Por ello, la defensa frente a las sequías y el esfuerzo secular por acrecentar las disponibilidades hídricas llenan las páginas más atrayentes de la historia agraria del sureste ibérico.

\section{Diluvios, aguaduchos y anegaciones}

A veces la precipitación cae con tal intensidad que los verbos «diluviar» o «jarrear», cuya acepción es la de llover copiosamente, resultan insuficientes para describir el aguacero, ya que entonces llueve a mares, se dice, significativa y gráficamente, que se abren las cataratas del cielo. Como se ha indicado, en el intervalo de pocas horas puede excederse e incluso duplicarse con creces la precipitación media anual. La perniciosidad de estos aguaceros y trombas depende ampliamente de la concentración horaria de la lluvia.

Para las precipitaciones mayores en 24 horas de cada uno de los años transcurridos entre 1951 y 2000, las intensidades máximas más frecuentes registradas en el Observatorio de Ciudad Jardín (Alicante) se sitúan entre 51 y $100 \mathrm{~mm} /$ hora, sólo dos bajan de 25 y seis suben de 200, de ellas dos rebasan ligeramente el umbral de los $300 \mathrm{~mm} /$ hora. No existe, empero, el menor asomo de duda de que esas cifras han sido superadas, con mucho, durante el mismo intervalo en otros puntos del sureste ibérico. Baste recordar lluvias tan intensas como las que anegaron la Vega Baja del Segura entre 4 y 5 de noviembre de 1987, con 316 mm medidos en Orihuela. Recordemos asimismo la mortífera tromba de agua que descargó sobre la ciudad de Alicante el 30 de septiembre de 1997.

Las catastróficas inundaciones de 19 de octubre de 1973, que produjeron enormes daños y más de un centenar de víctimas en las cuencas de los ríos Guadalentín, Almanzora y Adra, fueron motivadas por un proceso de «gota fría», que combinó casi todas las agravantes pluviométricas: en superficie, aire muy inestable y húmedo, con largo recorrido sobre el mediterráneo en el flanco meridional de un anticiclón de bloqueo y disparo en la 
vertical merced a la convección forzada impuesta por las alineaciones montañosas litorales y prelitorales, así como por la convergencia debida a la rotación ciclónica de vientos en el seno de una pequeña y nada profunda borrasca en el mar de Alborán. El ascenso del aire hasta la tropopausa, con génesis de gigantescos cumulonimbos, vino propiciado por la exageración del gradiente real producida por el embolsamiento de aire frío, a $-24^{\circ} \mathrm{C}$ en la topografía de $500 \mathrm{hPa}$, y la instalación de un mecanismo de divergencia por difluencia en delta plenamente operativo a esos niveles. Las precipitaciones fueron fortísimas en las cuencas fluviales mencionadas, sobresaliendo la localidad almeriense de Zurgena, que recogió $600 \mathrm{~mm}$ en tan sólo tres horas, con la particularidad de que 420 cayeron entre las 13 y 14 horas de ese 19 de octubre.

Casi cien años atrás, la memorable riada de «Santa Teresa», la mayor de que se tiene noticia histórica en el Segura, acaecida del 14 al 15 de octubre de 1879, con funestas consecuencias para el valle del Guadalentín, Huerta de Murcia y Vega Baja del Segura, tuvo por causa, en palabras de Pardé, «uno de los diluvios más mortíferos de los anales hidrológicos europeos». En el informe que sobre la inundación emitieron los ingenieros comisionados figura, entre otros, el dato siguiente: «A ocho kilómetros de Vélez Rubio y tres de la sierra de las Estancias existe el cortijo de Calderón, con un espacioso corral, en su centro había aquella mañana una caldera de cobre, de forma prismática, cuyas dimensiones eran dos metros de largo, medio de ancho y sesenta centímetros de profundidad. Al empezar la lluvia se encontraba del todo vacía y lejos de las paredes del corral; cuando hacía una hora que las nubes arrojaban el agua a torrentes, dispuso el dueño del cortijo trasladar la caldera al interior de la casa para recoger en ella las goteras que amenazaban anegar la planta baja, y se vio que no sólo estaba completamente llena, sino que rebosaba por todas partes». Es de notar que, si se admite esta referencia y no cabe desechar sin más su certeza, la precipitación media, durante al menos una hora, sobre algún punto de la cabecera del Guadalentín, habría resultado de $10 \mathrm{~mm} /$ minuto; sería éste un valor prácticamente límite, muy difícil, aunque no me atrevería a decir imposible, de superar.

Trascurrido casi un lustro de esta inundación, la peor que se recuerda en la cuenca del Segura y, sin duda, la de más resonancia europea, cuando ya se había padecido otra avenida de grandes proporciones, la de 21-22 de mayo de 1884, particularmente dañina para la Huerta de Orihuela, el Consejo de ministros resolvió el nombramiento, por Real Orden de 28 de junio de 1884, de una Comisión facultativa «que, estudiando las causas de las grandes inundaciones en las provincias de Murcia, Alicante y Almería, redactase los proyectos de las obras necesarias para remediar los efectos que producen en los valles del Segura y Almanzora» (GARCÍA y GAZTELU, 1886); a la cabeza de la misma se colocó al prestigioso Ingeniero de Caminos y Canales D. Ramón García Hernández.

Innecesario resulta encarecer que, como ocurriría un siglo después, con el Plan de defensas de las avenidas del Segura que, financiado tras la citada inundación de la Vega Baja el 4 y 5 de noviembre de 1987, acaba de ejecutarse; y ha sucedido invariablemente siempre que las mayores crecidas han acicateado las decisiones políticas sobre la materia, con exacta correspondencia cronológica. En el caso del Proyecto de obras de defensa contra las inundaciones en el valle del Segura de 1886 es bien patente que la designación de la referida Comisión facultativa vino motivada por la catastrófica riada de 14 de octubre de 1879 y la publicación en la Gaceta de Madrid acelerada, a última hora, por la avenida de 21-22 de mayo de 1884 .

El calendario de lluvias catastróficas en la región climática del sureste ibérico ofrece una notoria concentración de las mimas en los meses tardoestivales, entre mediados de septiembre y similares fechas de noviembre, con ápice en octubre, transcurre el período de máximo riesgo (Gil Olcina, 1989). El comportamiento térmico del Mediterráneo, 
con sus efectos higrométricos, constituye el factor que, conjugado de forma primordial, si bien no exclusiva, con las irrupciones de aire frío en altitud, confiere destacada primacía al otoño en estos desastres hidrológicos. En efecto, el responsable fluvial de los diluvios otoñales que esporádicamente azotan la región climática del sureste ibérico es el propio Mediterráneo, gigantesco reservorio de agua y calorías. Los mapas de isotermas marinas superficiales suelen mostrar, en coincidencia con estas lluvias torrenciales, temperaturas relativamente altas frente a las áreas afectadas. Así, por ejemplo, los mapas confeccionados por la Sección de Meteorología Hidrológica del Instituto Nacional de Meteorología para los días 20 y 21 de octubre de 1982 registran $22^{\circ} \mathrm{C}$ en aguas próximas a la costa alicantina; valores similares a los que ofrecía la superficie marina, también a las 6:00 horas, los días 18 y 19 de octubre de 1973 en los litorales de Alicante, Murcia y Almería. Especial mención merecen las temperaturas llamativamente altas observadas durante el verano $\left(26-29^{\circ} \mathrm{C}\right)$ y otoño $18-26^{\circ}$ C) de 1987 , gravísimo riesgo potencial que se tradujo en las desastrosas inundaciones que afectaron, entre otras comarcas valencianas, la Vega Baja del Segura.

Condiciones térmicas de esa índole propician que el mar trasfiera al aire enormes cantidades de vapor de agua y energía calorífica. Sirvan de paradigma los mapas de isolíneas de razón de mezcla concernientes a las topografías absolutas de 850 y $700 \mathrm{hPa}$ de los días 18 y 19 de octubre de 1982, con proporciones superiores a $10 \mathrm{~g} / \mathrm{Kg}$ de aire seco en el mar Balear, cara a las costas valencianas; las imágenes del satélite METEOSAT, tanto en radiación visible como en IR, confirmaban la existencia de una elevada tensión de vapor.

Como se ha dicho, de la segunda quincena de septiembre a mediados de noviembre, con culmen en octubre, se produce el período de máximo riesgo de los grandes aguaceros, tal y como atestiguan fehacientemente los anales hidrológicos alicantinos, murcianos y almerienses, sin perjuicio de que las riadas se anticipen a los primeros días de septiembre o retrasen a comienzos de diciembre; la temperatura de las aguas marinas superficiales constituye una dato de obligada referencia, que alerta sobre el grado de riesgo potencial. No faltan lluvias de invierno; sin embargo, los grandes diluvios históricos no menudean en dicha estación; son, por el contrario, raros. Chubascos de elevada intensidad horaria dibujan un pico secundario en primavera, aunque a distancia del máximo principal de otoño. En estío la infrecuente inestabilidad generalizada, susceptible de producir chaparrones de elevada intensidad horaria y aguaduchos, a veces de considerable violencia, suele obedecer en el sureste peninsular a la penetración de aire frío en altitud; estas situaciones atmosféricas son contadas en este época, si bien la última quincena de agosto, preludio del otoño, aventaja al mes y medio precedente (GIL OLCINA, 1989).

\section{Años secos y sequías prolongadas}

Los años de totales pluviométricos inferiores a la media anual menudean y también se repiten, con intervalos breves, secas duras pluviales. En los dos últimos siglos fueron largas y dañinas las de 1841-42, 1846-50, 1875-79, primera mitad de los ochenta de la centuria anterior y el período de 1993-1996.

Por su carácter de sotavento frente a la circulación general del oeste, cercanía a la subsidencia subtropical, vecindad de África, posición retraída en la cuenca del Mediterráneo occidental y amplia incidencia del relieve, que determina efecto foehn sobre el flujo del oeste y abrigo, con disimetría pluviométrica, respecto de las borrascas atlánticas, la región climática del sueste es la más expuesta de la península ibérica al riesgo natural de las sequías.

Actas capitulares, memoriales, expedientes de rogativas, libros de diezmos, cuentas de agua, anales hidrológicos, crónicas y otras variadas fuentes proporcionan multitud de noticias sobre las frecuentes sequías padecidas en la seca región climática del sureste 
ibérico. Aquí nos ceñimos a una sucinta referencia a las acaecidas desde 1800. Como «Año del hambre», por antonomasia, se menciona en la cuenca del Segura 1801, cuando hacía casi un lustro que los campos no se sembraban por falta de lluvia; otro «año de hambre» fue el de 1803. Particularmente seco resultó también 1815, en cuyo verano y otoño «se cruzaba a pie enjuto el Segura», el hambre causaba estragos y se multiplicaban las rogativas. Las peores sequías del siglo XVIII y primera mitad del XIX han permitido documentar, con todo lujo de detalles, las rogativas pro pluvia o ad petendaum pluviam realizadas por entonces en las sedes episcopales de Murcia y Orihuela, así como en la ciudad de Alicante.

Una terrible sequía durante el bienio 1841-42 hizo subir vertiginosamente en el Campo de Lorca, al igual que en otras comarcas del sureste ibérico, los precios de los alimentos y movió a las autoridades locales a solicitar del Gobierno auxilios y condonación de tributos. En su Memoria sobre el estado de la agricultura en la provincia de Alicante, el secretario de la Junta de Agricultura, Industria y Comercio informaba que «en la tristemente célebre sequía del año 1846 a 1850, cuyo recuerdo se conserva vivo aún en la memoria de los labradores alicantinos, casi todas las plantas perecieron, el algarrobo fue el único que pudo soportar tan terrible prueba». Íntima relación con la misma guarda el Real Decreto de 21 de marzo de 1850 , en el que, tras afirmar «De los puntos en que aparecen casi constantemente la falta de agua, las provincias limítrofes de Murcia y Almería son las que sufren más particularmente esta calamidad», el ministro de Comercio, Instrucción y Obras Públicas Seijas comunicaba al presidente de la Real Academia de Ciencias que «la Reina (Q. D. G.) se ha servido mandar que esa Real Academia sin levantar mano se ocupe y proponga al Gobierno lo conveniente para abrir un concurso a la mejor Memoria ... sobre las causas que producen las constantes sequías de las provincias de Murcia y Almería, señalando los medios de removerlas, si fuese posible; y no siéndolo, de atenuar sus efectos...», Según Couchoud y Sánchez Ferlosio, la gran sequía de este año, refiriéndose a 1850, «había de prolongarse aún por otros seis, de suerte que las gentes emigraban al África del Norte en tan grandes contingentes que la ciudad de Lorca y los pueblos de Alhama, Totana y Librilla, también del valle del Guadalentín, quedaron prácticamente despoblados» (COUCHOUD Y SÁNCHEZ, 1965). El 27 de agosto de 1874 el lecho del Segura quedó seco, hecho inserto en un período de sequía que se prolongaría hasta 1879 . Sin duda, la construcción de la tercera presa de Puentes, en régimen de concesión, entre 1881 y 1884 , debe mucho más al largo período de sequía que a la pavorosa crecida del Guadalentín del 14-15 de octubre de 1879.

En el transcurso del siglo XX sobresalen las secas de 1909-14, 1938-39, 1944-45, 197884 y 1993-96, sin olvidar los años secos de 1950, 1952, 1955, 1961, 1966, 1970, 1973, 1998, por más que en algunos de ellos ciertas comarcas de la región climática registraron aguaceros aislados y muy copiosos de extraordinaria intensidad horaria. El intervalo 197884 registró la más prolongada sequía del siglo $\mathrm{XX}$, y una serie de observatorios conocieron los años menos lluviosos de la serie 1961-1990; este fue el caso, entre otros, de: Orihuela (132 mm), Pinoso (117) y Aspe (119). Mínimos muy bajos, en distintos años, son asimismo los de Pilar de la Horadada (83 mm, 1985), Torrevieja (73 mm, 1961), Elche (129 mm, 1995), y, este último año, también San Miguel de Salinas (128 mm), Alicante (108) y Agost (107). Dadas las cosechas escasas o nulas por causa de las sequías, así como la pérdida de arbolado en las más intensas y duraderas, no puede sorprender que el refranero climático del sureste ibérico contenga múltiples referencias a éste riesgo natural, incluyendo dichos relativos a la irregularidad de las precipitaciones, a la espera anhelante de éstas en meses claves para la cerealicultura o a la seguridad que proporciona el riego con aguas del Segura, río alóctono de cabecera abundante. 
Las grandes secas del sureste peninsular han resultado, casi siempre, decisivas para la ejecución de obras hidráulicas controvertidas y costosas; no hay la menor duda, sobran datos concluyentes, del amplio condicionamiento de la política del agua, normas incluidas, por las temperies. Así, en la Exposición de Motivos de la Ley de 13 de diciembre de 1999, que modificó la Ley de Aguas de 2 de agosto de 1985, figura un párrafo tan expresivo como el siguiente: «... la experiencia de la intensísima sequía padecida por nuestro país en los primeros años de la década final de este siglo, impone la búsqueda de soluciones alternativas, que, con independencia de la mejor reasignación de los recursos disponibles, a través de mecanismos de planificación, permitan, de un lado, incrementar la producción de agua mediante la utilización de nuevas tecnologías, otorgando rango legal al régimen jurídico de los procedimientos de desalación o de reutilización, de otro, potenciar la eficiencia en el empleo del agua para lo que es necesario la requerida flexibilización del actual régimen concesional a través de la introducción del nuevo contrato de cesión de derechos al uso del agua, que permitirá optimizar socialmente los usos de un recurso tan escaso, y, por último, introducir políticas de ahorro de dicho recurso...».

\section{Umbrales de la región climática}

Como se ha reiterado, el rasgo definitorio esencial de la región climática del sureste ibérico es la aridez. Resulta éste, sin embargo, un concepto complejo, cuya expresión numérica por un coeficiente, ante la seria dificultad de ponderar la incidencia de las variables implicadas, suele efectuarse de manera simplificada, prescindiendo de la mayoría o práctica totalidad de aquéllas, mediante el cálculo de índices termopluviométricos, de acuosidad o aridez; otra vía es la nueva indicación del número de meses que, al cabo del año, merecen a los diferentes autores, con opiniones asimismo distintas, la consideración de secos. Por ello, no debe extrañar que la primera y meritoria propuesta para delimitar la susodicha región climática, formulada por Vilá Valentí (1961), dejase de lado isóxeras y otras isoaritmas, para optar, con criterio plausible, por una isoyeta media anual, en este caso la de $300 \mathrm{~mm}$, que compendiase el hecho climático. La tendencia posterior ha sido la de revisión al alza; así, Martín Vide y Olcina Cantos (2001) se inclinan por 350, altura que, por nuestra parte, elevamos a $375 \mathrm{~mm}$.

Este volumen medio obedece a una aplicación corregida del criterio de Köppen; recordemos, al respecto, que el umbral correspondiente en este supuesto, con verano seco, es el de $2 \overline{\mathrm{T}}\left({ }^{\circ} \mathrm{C}\right)=\mathrm{P}(\mathrm{cm}$. $)$, y también que las temperaturas medias anuales de algunos observatorios surestinos exceden de $18^{\circ} \mathrm{C}$ (18,5 Almería; 19, Águilas); y, además, es preciso contar que la eficacia de la precipitación media viene disminuida y menguada por su elevada concentración horaria, fuerte irregularidad interanual, veranos extremadamente secos, años con totales inferiores a las exiguas medias de las series, duras y prolongadas sequías, y, muy en primer término, una evapotranspiración potencial que, como mínimo, duplica con creces los registros pluviométricos medios de los observatorios menos desfavorecidos.

La escasez de precipitaciones y su mermada eficacia constituyen, sin duda, la característica primordial de la región geográfica del sureste ibérico, pero no bastan para definirla. Observatorios de comarcas aledañas con menos de $375 \mathrm{~mm}$ no pertenecen, notoriamente, a ella; sirvan de ejemplo algunos de los ubicados en el Alto Vinalopó, Altiplano de JumillaYecla o en la propia Mancha albaceteña. Aunque no se produzca aumento suficiente de las precipitaciones, continentalización e incremento de altitud, con endurecimiento del invierno, descenso de la temperatura media anual y mayor amplitud anual, excluyen de la región considerada. A la que nos adscribimos espacios con temperatura media anual inferior a $16^{\circ}$, amplitud térmica superior a $18^{\circ}$ y media mensual por bajo de $8^{\circ} \mathrm{C}$. Como se ha dicho, la 
región geográfica del sureste ibérico es una fachada mediterránea apoyada en las montañas, integrada por tierras litorales y prelitorales, un sotavento de longitud y relieve, resguardado de la circulación general del oste por el bastión de las cordilleras béticas.

A tenor de los requisitos exigidos, la región geográfica del sureste peninsular englobaría, por completo o mayoritariamente, las comarcas y unidades siguientes: Marina Baja, Campo de Alicante, Bajo y Medio Vinalopó, Bajo Segura, Campo de Cartagena, Vega Media del Segura, Alto Guadalentín y costa aledaña, Bajo Guadalentín, litoral almeriense, Medio y Bajo Almanzora, Campo de Níjar, corredor de Tabernas-Sorbas, así como subcuencas inferiores de los ríos Nacimiento, Antas, Aguas y Andarax.

Raramente, como sucede en el cabo de la Nao, puede marcarse una frontera rotunda y nítida a la región climática del sureste peninsular, orlada de áreas de transición, ya sean comarcas limítrofes de las indicadas o porciones de ellas mismas. Las repercusiones climáticas de la altitud y el progresivo distanciamiento del mar, combinadamente, con una u otra primacía, originan cambios que anuncian la proximidad de las tierras meseteñas o de montaña, entre otras, ese carácter de transición asumen las comarcas del Alto Vinalopó, Altiplano de Jumilla-Yecla, Vega Alta del Segura, Cuenca de Mula, altas tierras septentrionales del Campo de Lorca, altiplanicie de los Vélez, Alto Almanzora, valle superior del Andarax y Baja Alpujarra.

La percepción del medio de la región analizada quedaría incompleto por entero si olvidásemos el aspecto habitual del ciclo, reflejado cabalmente en dos expresiones seculares antedichas: «Lorca es la ciudad del sol» en el «serenísimo reino de Murcia», es decir, débil nubosidad, abundancia de cielos despejados y muchas horas de sol al año; la media de estas últimas no baja de 2.800, y pasan de 1.100 entre octubre y marzo: Almería registra un máximo de 343 horas en julio, con un mínimo, notoriamente alto, de 181 en diciembre. En la mayoría de la región climática, y en la práctica totalidad de tierras murcianas y almerienses adscritas a la misma, los días despejados duplican a los cubiertos o rondan esta relación.

Como se ha indicado, la evapotranspiración potencial, que salvo años excepcionalmente lluviosos agota pronto las exiguas reservas de agua constituidas en otoño e invierno, duplica la precipitación media anual de los observatorios menos desfavorecidos calculada por el método de Thornthwaite y lo hace, con creces, si se utiliza el de Turc.

La práctica totalidad de los observatorios de la región climática delimitada merecen el símbolo B en la notación de Köppen, e decir, climas secos, si bien con distinción entre esteparios y desérticos. Estos últimos pertenecen al tramo costero más árido entre los cabos Tiñoso y de Gata, con las siglas BWhs», esto es, desérticos cálidos, con verano muy seco y repuntes nada cuantiosos, descontados esporádicos diluvios, de otoño y primavera; baste señalar que, en los dos observatorios citados, las lluvias, sumamente irregulares, bajan de $200 \mathrm{~mm}$ para cualquier serie y en alguna no llegan a 150, aunque supongan un cierto suplemento las precipitaciones ocultas en forma de rocío, ya que de otro modo resultaría difícil explicar el vigor de algunos poblamientos vegetales, tales como la serie semiárida Chamaeropo-Rhammeto lycioides y las semiárido-áridas Mayteno Europaei-Periploceto Angustifoliae y Zizipheto loti, sobre todo de la primera de las mencionadas en el propio Cabo de Gata; con temperaturas medias anuales de $18-19^{\circ} \mathrm{C}$, invierno muy suave (enero, $12-13^{\circ} \mathrm{C}$ ), práctica ausencia de heladas, y verano caluroso (agosto, 26-27 ${ }^{\circ} \mathrm{C}$ ), la ETP en los cálculos más moderados sobrepasa $1,5 \mathrm{~m}$ al año, con intenso y casi permanente déficit hídrico en el suelo. Acusada es también la aridez en el resto de observatorios, definidos como esteparios de verano seco y máximos de precipitaciones en otoño y primavera, diferenciados térmicamente según la media anual llegue o no a $18^{\circ} \mathrm{C}$, con las variedades BShs» y BSjs». Son de destacar, junto a la parvedad de las precipitaciones (200-350 mm anuales), su elevada irregularidad interanual (coeficientes $4-6$ ), la torrencialidad de las 
mismas, un estío muy seco y, como obligado corolario, un intenso y prolongado déficit hídrico. A causa de éste, los esquimos de la trilogía mediterránea resultan notoriamente inciertos y aleatorios en secano.

En este ámbito, la aridez constituye asimismo referencia esencial en la clasificación de Thornthwaite, que encuadra los observatorios meteorológicos de la región geográfica del sureste ibérico en los tipos semiárido y árido mesotérmico, sin superávit hídrico en invierno; con índices de aridez superiores a 60 e hídricos por bajo de $-35^{\mathrm{a}}$, alcanzando casi todos en la franja costera entre los cabos de Santa Pola y Gata, Depresión Prelitoral Murciana y tierras prelitorales almerienses valores mayores de 70 y menores de -40 respectivamente. Ello ilustra bien sobre la dificultad y riesgo del cultivo en secano, y evidencia el desafío a que ha dado respuesta el hombre para hacer de este espacio el gran abastecedor de la Unión Europea en hortalizas fuera de estación.

\section{De la hipótesis de cambio climático regional a la global: interrogantes e incertidumbres}

En una región geográfica articulada sobre la base y en respuesta a la aridez del medio, resulta obligado que cualquier supuesto o conjetura sobre cambio climático analice, en primer término, la evolución de las precipitaciones. Así sucede ahora, y también ocurrió en el pasado, cuando mediado el ochocientos tomó cuerpo la hipótesis tardoilustrada de disminución de aquéllas, relacionando con esta suposición la frecuencia e intensidad de las secas en el sureste ibérico. La peor de las sequías documentadas en tierras surestinas es la de 1846 a 1850; íntima relación con la misma guarda el Real Decreto de 21 de marzo de 1850, a través del cual el ministro de Comercio, Instrucción y Obras Públicas Seijas comunicaba al presidente de la Real Academia de Ciencias que «la Reina (Q.D.G.) se ha servido mandar que esa Real Academia sin levantar mano se ocupe y proponga al Gobierno lo conveniente para abrir un concurso que premie a la mejor Memoria» sobre las causas que producen las constantes sequías en las provincias de Murcia y Almería, señalando los medios de removerlas, si fuese posible; no siéndolo, de atenuar sus efectos ...» Tras esta convocatoria subyacía la idea muy extendida entonces, cuando finalizaba la pulsación climática denominada, quizá con exageración, «Pequeña Edad del hielo», que la dureza y elevada frecuencia de las sequías - dos muy severas en la década de los cuarenta (1841-42 y 1846-50)- tenía por causa la deforestación, acogiendo así las instituciones científicas de la época y la Administración pública una primera hipótesis de supuesto cambio climático por degradación humana del medio natural.

Con arreglo a esa propuesta, otro Real Decreto de 30 de marzo de 1850 convocó el referido certamen (GIL OLCINA, 2007). Resultó premiada la Memoria sobre las causas meteorológico-físicas que producen las constantes sequías de Murcia y Almería, señalando los medios de atenuar sus efectos, de Manuel Rico y Sinobas, y obtuvo el accésit José de Echegaray, padre del famoso escritor, político y matemático, con su Memoria sobre las causas de la sequía de las provincias de Almería y Murcia, y de los medios de atenuar sus efectos, aunque muy probablemente la no indicación del segundo apellido, dada la coincidencia de nombre, deba entenderse como el deseo de hacer patente la colaboración en la misma de padre e hijo, Las tesis de ambas Memorias eran dispares y opuestas: José de Echegaray y Elguezabal, catedrático de Agricultura en el Instituto de Segunda Enseñanza de Murcia, defendía como determinante la relación deforestación-sequía, de modo que propugnaba no sólo la repoblación forestal, sino una agricultura que asociase ampliamente las cosechas de suelo y vuelo. A diferencia, Rico y Sinobas, catedrático de Física Superior en la Universidad de Valladolid, comenzaba por rechazar la existencia de cambio climático en el sureste ibérico («Nuestro clima Puni-Ibérico no ha cambiado respecto a las aguas hidrometeóricas; 
hubo sequías en tiempos más antiguos que en el de los árabes...»), donde los episodios de sequía, frecuentes e intensos, se hallaban inequívocamente documentados.

Todo ello no sería óbice para que, siglo y medio después, la titular del Ministerio de Medio Ambiente volviese a enmarcar los fenómenos de sequía, particularmente intensos y reiterados durante el último cuarto del siglo XX en el sureste ibérico, sin reserva ni cautela alguna, en el hipotético y controvertido cambio climático por efecto invernadero. Sin embargo, la tendencia pluviométrica para la segunda mitad del siglo XX que revele el análisis, con el riguroso método de Alexandersson (QUEREDA, MONTÓN, et alii, 2001), de las series de treinta observatorios de la región geográfica del sureste ibérico, no presta base, en modo alguno, a esta clase de aseveraciones, dado que resulta una reducción media irrelevante, del orden de 0,6 mm/año, inexistente, además, si se excluye el bienio marcadamente seco de 1998-2000. En suma, la disminución total de $30 \mathrm{~mm}$ en el período indicado carece de toda significación estadística, máxime con el amplio margen de variabilidad natural de un régimen pluviométrico caracterizado primordialmente por las notas de escasez e irregularidad. En idéntico orden, la incidencia de prolongados e intensos períodos de sequía en el último cuarto de la pasada centuria, con dos de tanta trascendencia para las políticas del agua en el ámbito de referencia y la nación toda como los de 1978-82 y 1992-95, no deviene excepcional por la condición extremada de aquél y la presencia habitual de este tipo de episodios.

Con todo, no cabe olvidar que efecto básico del cambio climático por efecto invernadero sería el calentamiento global, que modificaría otros elementos y la propia circulación atmosférica general. Por ello, reviste singular interés la consideración tanto de los valores de temperatura y oscilación térmica como de humedad específica, es decir, el contenido en vapor de agua, principal gas de efecto invernadero, y de la nubosidad, que retiene calor oscuro, pero restringe, por su elevado albedo, la aportación del luminoso.

En perspectiva histórica, queda fuera de toda duda, al encontrarse sólidamente documentada, la existencia de una pulsación fría desde el siglo XIV a comienzos del XIX. Consituye dato generalmente admitido que, entre 1700 y 1880 , la temperatura media habría sido inferior, al menos $1^{\circ} \mathrm{C}$, a la registrada en el inicio del siglo $\mathrm{XX}$, con datos notoriamente más elevados que los actuales de nivosidad e innivación en las montañas que ciñen la región geográfica del Sureste Ibérico. Desde 1880 a 2000, la recuperación íntegra habría sido de $0,7-0,8^{\circ} \mathrm{C}$, incluida la que quepa atribuir a la «isla de calor urbana». En todo caso, no se trataría de un incremento paulatino, sino discontinuo y dispar, ya que tras una primera fase de aumento hasta 1945, se habría producido un suave enfriamiento y luego una mayor elevación a partir de 1975. Durante la segunda mitad del novecientos, las temperaturas de los observatorios urbanos de la región considerada se habrían elevado en torno a $0,8^{\circ} \mathrm{C}$, y menos de la mitad los ubicados en medio rural estricto; descontada la incidencia urbana y asumido que los de ámbito rural representasen la tendencia natural, el incremento en dicho período no pasaría de $0,3^{\circ} \mathrm{C}$. Cuestión controvertida, y hasta ahora sin explicación generalmente aceptada, es que ese aumento, resultante de la elevación de las mínimas, deba relacionarse con menores pérdidas por irradiación a causa de mayor nubosidad. Obviamente, ello requería justificar por qué la mayor nubosidad sólo revestiría carácter nocturno. Empero, con ser esta interrogante de indudable trascendencia, resulta otra más, una incógnita a despejar entre las innumerables que plantea una cuestión tan compleja como el hipotético cambio climático por efecto invernadero. No hemos encontrado datos con que avalarlo en la región geográfica del Sureste Ibérico, quizá por qué con un clima hecho de fuertes contrastes, particularmente pluviométricos, no resulte la más idónea para dectar un proceso donde, en su caso, interaccionan infinidad de variables, posiblemente más fáciles de identificar y ponderar en otros ámbitos donde los episodios extremos no sean norma, y resulten verdaderamente atípicos. 


\section{Bibliografía}

ASOCIACIÓN METEOROLÓGICA ESPAÑOLA (1990): XVIII Jornadas Científicas. «Peculiaridades del clima del Sureste Peninsular», Madrid, 207 págs.

CAPEL MOLINA, J. J. (1974): Génesis de las inundaciones de octubre de 1973 en el Sureste de la Península Ibérica», Cuadernos Geográfícos, no 4, págs. 149-166.

CAPEL MOLINA, J. J. (1983): «Distribución de la precipitación en el sureste español», Bol. Inst. Est. Almerienses, págs. 27-36.

CAPEL MOLINA, J. J. (1985): «Contribución geográfica al estudio de la aridez en el sureste de España», Madrid, AME, págs. 97-134.

CAPEL MOLINA, J. J. (1986): El clima de la provincia de Almería, Almería, Monte de Piedad y Caja de Ahorros de Almería, 125 págs.

CAPEL MOLINA, J. J. (2000): El clima de la península Ibérica, Barcelona, Ariel, 281 págs.

CAPEL MOLINA, J. J. y OLCINA CANTOS, J. (1993): «Ondas cortas atmosféricas estivales y fenómenos tormentosos con granizo en el Sureste peninsular Ibérico», Papeles de Geografía, $\mathrm{n}^{\mathrm{o}} 17$, págs. 21-42.

COUCHOUD SEBASTÍA, R. Y SÁNCHEZ FERLOSIO, R. (1965): Efemérides hidrológicas y fervorosas, Madrid, Imp. Silverio Aguirre, 104 págs. (Reedición en facsímil, Colegio de Ing. de Caminos, Canales y Puertos de Murcia, 1984).

ECHEGARAY, J. DE (1851): Memoria sobre las causas de la sequía de las provincias de Almería y Murcia, y de los medios de atenuar sus efectos, escrita con arreglo al programa del real decreto de 30 de marzo de 1850. Premiada con el accésit por la Real Academia de Ciencias, Madrid, Imprenta del Ministerio de Comercio, Instrucción y Obras Públicas, 123 págs.

FONT TULLOT, I. (1983): Climatología de España y Portugal, Madrid, INM.

FONT TULLOT, I. (1983): «Algunas observaciones sobre las lluvias excepcionales en la vertiente mediterránea española», Est. Geogr., nº 170-171, págs. 55-60.

GALLEGO JIMÉNEZ, F. (1996): Situaciones de flujo mediterráneo y precipitaciones asociadas. Aplicación a la predicción cuantitativa en la cuenca del Segura. Murcia, Univ. de Murcia, 412 págs.

GARCÍA HERNÁNDEZ, R. Y GAZTELU MARITORENA, L. (1886): Proyecto de obras de defensa contra las inundaciones en el valle del Segura, edición facsímil, Murcia, Confederación Hidrográfica del Segura, 2001, LXX + $131+115$ págs.

GARCÍA DE PEDRAZA, L. (1983): «Situaciones atmosféricas tipo que provocan aguaceros torrenciales», Est. Geogr. no 170-171, págs. 61-73.

GIL OLCINA, A. (1983): «Inundaciones de octubre de 1982 en el Campo de Alicante», Est. Geogr., $\mathrm{n}^{\circ}$ 170-171, págs. 121-141.

GIL OLCINA, A. (1989): «Causas climáticas de las riadas», Avenidas fluviales e inundaciones en la cuenca del Mediterráneo, CAM e Inst. Univ. de Geografía, págs. 15-30.

GIL OLCINA, A. (1993): La propiedad de aguas perennes en el sureste ibérico, Univ. de Alicante, 191 págs.

GIL OLCINA, A. (2001): «Secas históricas en la región climática del sureste ibérico», Causas y consecuencias de las sequías en España, págs. 161-186.

GIL OLCINA, A. (2004): «Actuaciones pioneras para riego y defensa contra avenidas en los ríosramblas surestinos», Alteración de los regímenes fluviales peninsulares, Fundación CajaMurcia, 683 págs.

GIL OLCINA, A. (2007): «Sequía de 1846-50 e hipótesis de cambio climático por deforestación en el sureste ibérico», Estudios Geográficos, n ${ }^{\circ}$ 262, págs. 91-117.

GIL OLCINA, A. y MORALES GIL, A., ed. (2001): Causas y consecuencias de las sequías en España, Alicante, CAM e Inst. Univ. de Geografía, 574 págs.

GIL OLCINA, A., MORALES GIL, A. y TORRES ALFOSEA, F. J. (2004): «Aridez, salinización y agricultura en el Sureste Ibérico», Fundación Ramón Areces y Fundación Instituto Euromediterráneo de Hidrotecnia, Madrid. 255 págs.

LÓPEZ GÓMEZ, A. (1983): «Las lluvias catastróficas mediterráneas», Est. Geógr., nº 170-171, págs. 11-30. 
LÓPEZ GÓMEZ, A. y LÓPEZ GÓMEZ, J. (1959): «El clima de España según la clasificación de Köppen», Est. Geógr., 72, págs. 167-188.

MARTÍN VIDE, J. (1992): «Características extremas de la precipitación en la España mediterránea» Inundaciones y redes de drenaje urbano, Barcelona, Univ. Pol. de Cataluña y Colegio de Ingenieros de Caminos, Canales y Puertos, págs. 23-39.

MARTÍN VIDE, J. y OLCINA CANTOS, J. (2001): Climas y tiempos de España, Madrid, Alianza Editorial, 258 págs.

MIRÓ-GRANADA GELABERT, J. (1983): «Consideraciones generales sobre la meteorología de las riadas en el Levante español», Est. Geógr., nº 170-171, págs. 31-54.

MORALES GIL, A., OLCINA CANTOS, J. y RICO AMORÓS, A. (2000): «Diferentes percepciones de la sequía en España: adaptación, catastrofismo e intentos de corrección», Inv. Geogr., n 23, págs. 5-46.

OLCINA CANTOS, J. (1995): Episodios meteorológicos de consecuencias catastróficas en las tierras alicantinas (1900-1964), Inst. «Juan Gil-Albert», 376 págs.

OLCINA CANTOS, J. y RICO AMORÓS, A. M. (1999): «Mapa de precipitaciones máximas y riesgo de inundaciones en la provincia de Alicante», La Climatología española en los albores del siglo XXI, Barcelona, Asociación Española de Climatología y Oikos-Tau, págs. 353-361.

QUEREDA SALA, J. (1989): «Las interacciones atmósfera-océano en la climatología del Mediterráneo occidental», Avenidas fluviales e inundaciones en la cuenca del Mediterráneo Occidental, CAM e Inst. Univ. de Geografía, págs. 67-87.

QUEREDA SALA, J. y MONTÓN CHIVA, E. (1994): Las lluvias torrenciales en la Comunidad Valenciana. Interacciones atmósfera-mar, Castellón, Dip. de Castellón, 190 págs.

QUEREDA SALA, J., MONTÓN CHIVA, E. ET ALII. (2001): Nuestro porvenir climático: ¿Un escenario de aridez?, Universitat Jaime I, 223 págs.

RICO y SINOBAS, M. (1851): Memoria sobre las causas meteorológico-físicas que producen las constantes sequías de Murcia y Almería, señalando los medios de atenuar sus efectos (Premiada por el Ministerio de Comercio, Instrucción y Obras Públicas, a juicio de la Real Academia de Ciencias, en el certamen abierto por real decreto de 30 de marzo de 1850). Madrid, Imprenta a cargo de D. S. Compagni, 391 págs + 4 figs.

RIOSALIDO, R. Y CARRETERO, O. (1998): «Sistemas convectivos de mesoscala: climatología mediante imágenes de satélite», Nimbus, $n^{\circ} 1$, págs. 113-136.

VILÁ VALENTÍ, J. (1961): «La lucha contra la sequía en el SE. español», Est. Geógr., nº 82, págs. 25-48. 